euclidian from non-euclidian geometry.* Or, more directly, we might adopt the really sensible assumption of Clavius, that the "line of equal distance" is straight. Or, again, we might assume that it is possible to construct a rectangle; remarking that if three sides be constructed, the fourth must be either greater than, or equal to, or less than the base, and that the simplest system, that of equality, is chosen because of its conformity with universal consent. It might also be said that that system is the only one consistent with the received idea, that if a solid be moved along a straight line without revolving, all points of it describe equal distances ; for if this be admitted, it follows that two perpendiculars to the same line are everywhere equally distant.

Morristown, October 18, 1892.

\title{
A NEW LOGARITHMIC TABLE.
}

Tables des Logarithmes a huit décimales des nombres de $1 \grave{\alpha}$ 125000, et des fonctions goniométriques sinus, tangente, cosinus et cotangente de centimiligone en centimiligone et de microgone en microgone pour les 25000 premiers microgones, et avec sept décimales pour tous les autres microgones. Par J. de MeNdiź́Bal-Tamborred, Ingénieur-Géographe. Paris ; Hermann, 1891. Folio, pp. 320.

IN this folio rolume, piously dedicated to the memory of Le Verrier, is contained a very extended table of logarithms, differing materially from any of its predecessors. The unit which the author has adopted for decimal subdivision, in place of the degree, is not the quadrant, or unit of the recent eight-figure tables issued by the French government, but the entire circumference. The author considers this unit more logical, and instances two advantages peculiar to it. These are, first, that the unit of measure for time being the day, the corresponding unit for angle should be the whole circle, and secondly, in the case of angles exceeding the circumference, the trigonometric functions can be found by using simply the fractional part of the angle. The author proposes the name gone for his unit, and adopts the symbol $\gamma$ to represent it. The lower units will then be décigones, centigones ... microgones, the last being $1 / 1000000$ of the circumference, and equivalent to $1^{\prime \prime} .296$. The first table gives eight-figure logarithms for

* Referred to as "the axiom of similars" by Sir Richard Ball in the article " Measurement" of the Encyclopodia Britannica. The axiomatic character of geometric proportion is urged strongly by De Morgan, in the article "Proportion" of the Penny Cyclopcedia. 
all numbers from 1 to 125000 , and the values of $S$ and $T$ used to obtain the sines and tangents of small arcs. This is followed by the trigonometric table, in which the functions are given for every microgone. Eight decimals are used for each microgone up to 25000 , after which the eighth decimal is omitted from all but the centimiligones.

In order to secure accuracy the author has made a comparison with the famous manuscript tables of Prony, preserved at Paris. The proof sheets were afterwards compared with the tables already mentioned as having been issued recently by the French government. Moreover, a final check was secured by comparing in every case the sum of the cosine and tangent with the sine. In the course of his comparisons $\mathbf{M}$. Mendizábal-Tamborrel found eight errors in the French tables. These have been communicated by him to the Académie des Sciences at Paris. Much praise is due the author for the excellent manner in which he has dealt with the difficult problem of arranging the logarithms upon the pages. Old style type is used, and suitable tables of proportional parts are given whenever possible.

In a short notice like the present, it does not seem desirable to enter upon the question of the best method of angular measurement. But it is very important to have extended tables in existence arranged according to the various proposed methods : and to the author of the present work is therefore due the credit of having performed a considerable service to science. That this opinion is very generally held, is sufficiently shown by the list of subscribers to the present work, which includes the names of nearly all the most distinguished astronomers and geodesists.

HAROLD JACOBY.

\section{NOTES.}

A Regular meeting of the New York Mathematical SocIETY was held Saturday afternoon, October 8, at half-past three o'clock, the president in the chair. The following persons having been duly nominated, and being recommended by the council, were elected to membership : Professor Levi Leonard Oonant, Worcester Polytechnic Institute ; Dr. George Daniel Gable, Lafayette College ; Professor William Jasper Kerr, State University of Utah; Mr. John Cunningham McLennan, University of Toronto ; Mr. Joseph Clement Pfister, Columbia Oollege. The secretary announced the publication and distribution since the last meeting of a pamphlet containing a new list of members, the constitution, by-laws, etc. 